\title{
Invitation to Attend the Fall Meeting of the Swiss Chemical Society in Lausanne, on Wednesday, September 12, 2007
}

On behalf of the Swiss Chemical Society and of the Organizing Committee, we are pleased to invite you to attend the SCS Fall Meeting 2007. Following the tradition of alternating locations of this event, the Ecole polytechnique fédérale de Lausanne (EPFL) is proud to host this year's meeting on its campus.

The new academic calendar that has been recently imposed on all Swiss universities means that the Fall Meeting, which is traditionally organised ten days before the beginning of the academic term, will actually have to take place from now on during late summer. Despite this earlier schedule, we are confident that this event will remain the largest scientific congress organised annually in Switzerland.

The SCS Fall Meeting 2006 in Zurich already hosted a symposium of the Polymer Group of Switzerland. This body officially merged last June with the Swiss Chemical Society to create the new Division 'Polymers and Colloids'. We are happy to welcome these researchers and colleagues among our community and to fully incorporate this year an additional session on Polymer Science in our scientific program.

430 submitted scientific contributions have been accepted in the fields of analytical chemistry, medicinal chemistry, computational chemistry, inorganic and coordination chemistry, organic chemistry, physical chemistry, and polymer science. Plenary sessions and eight parallel sessions will offer a total of 118 invited lectures and contributed talks. In addition, 318 posters will be on display. As in past meetings, there will be a jury to select the best oral and poster presentations, for which prizes will be awarded.

We hope that this lavish scientific program will interest you, and we encourage you to come to Lausanne. Your participation during presentations and discussions will make the Fall Meeting of the Swiss Chemical Society 2007 again a grand success. We look forward to seeing you there.

Prof. Heinz Berke

Chairman of the Division of Chemical Research
Prof. Jacques-E. Moser

Chairman of the Organising Committee 